\title{
Urban Solid Waste Generation and Management Issues: Analysis of Solid Waste Disposal in the Kattankudy Urban Council Area, Sri Lanka
}

\author{
Anver M.C.M. ${ }^{1}$ and Sivarajah P. ${ }^{2} *$ \\ ${ }^{1}$ Postgraduate Studies Unit, Faculty of Commerce and Management, Eastern University, \\ Chenkalady-30350, Sri Lanka \\ ${ }^{2}$ Department of Agricultural Economics, Faculty of Agriculture, Eastern University, \\ Chenkalady-30350, Sri Lanka \\ "sivaponniah@yahoo.com
}

\begin{abstract}
Urban solid waste management is a problem for local authorities of many cities in Sri Lanka, due to rapid population growth and changes in consumption patterns of urban households, leading to large quantity of solid waste generation. This paper addresses solid waste management in the Kattankudy urban council area in Sri Lanka. The study used mainly secondary data collected from the Urban Council office and some discussions with UC officials dealing with waste management. Total waste generation per day was $37,368 \mathrm{~kg}$, total bio waste per day of $21,371 \mathrm{~kg}(57.20 \%)$, total Non-bio waste per day $15,829 \mathrm{~kg}(42.36 \%)$, and total special waste per day $168 \mathrm{~kg}(0.44 \%)$. Total waste generated per day was composed of bio waste of $21,371 \mathrm{~kg}(57.20 \%)$, total Non-bio waste of $15,829 \mathrm{~kg}(42.36 \%)$, and total special waste of $168 \mathrm{~kg}(0.44 \%)$. The total waste generation per person per day was $0.753 \mathrm{~kg}$, $0.43 \mathrm{~kg}$ of biodegradable waste, $0.32 \mathrm{~kg}$ non-biodegradable waste and $0.003 \mathrm{~kg}$ special waste per person per day. It was estimated that about $54 \%$ of the revenue collected by the Kattankudy UC was being spent on solid waste collection activities, which has hindered use of funds for other essential service provision such as repairs to roads, water supply and sanitation facilities. Findings indicate that massive amounts of solid waste are generated which are difficult to collect and dispose. Some policy issues are discussed for a better waste management strategy.
\end{abstract}

Keywords: Solid waste, Urban council, Households, Waste disposal, Expenditure 